\title{
Plano estratégico para o ambiente acadêmico: estudo de caso em grupo de pesquisa da Universidade Federal do Paraná
}

\author{
Ana Carolina Greef', Francisco Daniel de Oliveira Costa², Newton Corrêa de Castilho Junior ${ }^{3}$
}

\begin{abstract}
Resumo
Introdução: A competição entre concorrentes atuantes no ambiente acadêmico tem características distintas daquela entre agentes inseridos no mercado competitivo organizacional. Os objetivos estratégicos da primeira categoria de concorrentes referem-se à visibilidade e ao posicionamento no mercado de pesquisadores, grupos de pesquisa, Universidades. Assim, a aplicação de um plano estratégico ao Grupo de Pesquisa Aplicada em Ciência, Informação e Tecnologia (GPCIT), poderá - potencialmente - agregar valor a processos e decisões neste ambiente. Método: Pesquisa aplicada envolvendo os seguintes passos: caracterização do ambiente; identificação da principal demanda em relação tipo de planejamento e voltada para a definição do foco; síntese do posicionamento do ambiente frente a seu mercado de atuação; diagnóstico de fatores internos e externos; detalhamento da competência central; definição de direcionamento estratégico; esboço da estratégia nos niveis de negócios, colaboração e crescimento. Resultados: As características da cultura interna e externa do GP-CIT são favoráveis à realização do planejamento estratégico com vistas a reforçar o potencial de recursos, competências e oportunidades. Tais aspectos fundamentaram o delineamento da direção estratégica a ser seguida pelo Grupo no ambiente acadêmico, com foco em uma visão de longo prazo e apoio em missão, objetivos e valores de negócio. Estratégias de diferenciação, colaboração e crescimento foram formuladas conforme objetivos de atuação do GP-CIT no ambiente acadêmico, considerando-se a dinâmica competitiva a ele inerente. Conclusões: A implementação das estratégias deve seguir passos cautelosos e decisões bem fundamentadas, agregando perspectivas sólidas e competitivas à atuação. 0 pensamento estratégico, enquanto visão holística, passa a ser inserido na cultura do Grupo de maneira a modificar não apenas processos a ele relacionados, mas todo o paradigma de atividades e competições no ambiente acadêmico.
\end{abstract}

\section{Palavras-chave}

Planejamento estratégico; Universidade Federal do Paraná; Grupos de pesquisa; Competitividade; Gestão da informação.

\section{Introdução}

Encaminhar uma organização "ao cumprimento de seus objetivos fundamentais" (HARRISON, 2005, p. 36) caracteriza um dos objetivos que compõem o planejamento estratégico, efetivado não apenas por diretrizes estabelecidas, mas também por "uma perspectiva integrada do empreendimento" (HARRISON, 2005, p. 40).

Ciclos analíticos e planos de ação integram o composto metodológico do planejamento $\mathrm{e}$ pensamento estratégicos, originando um plano que apresenta à organização a sua posição atual no mercado de atuação e meios para atingir determinada posição futura, seja neste mesmo mercado ou em ambientes diferenciados.

O ambiente acadêmico apresenta, inerentemente, um cenário competitivo específico que se diferencia do contexto mercadológico quanto à natureza de competições entre os atores. Nesse, Universidades, grupos de pesquisa e pesquisadores atuam conforme objetivos de longo prazo e buscam visibilidade e posicionamento no mercado frente aos demais competidores. 
Essa realidade reflete-se na atuação do Grupo de Pesquisa Aplicada em Ciência, Informação e Tecnologia (GP-CIT), da Universidade Federal do Paraná, cujos projetos e ações têm potencial considerável em termos de contribuição à comunidade científica e provimento de visibilidade ao Grupo em si. Em complemento, recursos e relações por ele mantidos têm quantidade, qualidade e características valiosas, raras, inimitáveis e organizáveis que encaminham o GP-CIT à vantagem competitiva.

Um plano estratégico desenvolvido no âmbito do Grupo viria a alavancar a administração desses potenciais em direção a uma posição futura desejada, determinando objetivos, indicadores e metas para atingir tal posicionamento e alinhando táticas e operações cotidianas a esses aspectos de maior abrangência.

A premissa acima apontada dá origem ao estudo de caso aqui descrito, no qual detalhamse aspectos teóricos e práticos relacionados à elaboração do plano estratégico, de modo que esse atenda necessidades estratégicas por parte do GPCIT. Esta pesquisa caracteriza-se como aplicada - mesclando vertentes teóricas e práticas ao longo de sua descrição - utilizando técnicas para obtenção de resultados, adaptadas do tradicional contexto corporativo à academia. São elas, na sequência utilizada para o desenvolvimento da pesquisa:

a) caracterização do ambiente a ser avaliado e ao qual deve ser aplicado o planejamento estratégico;

b) identificação da principal demanda do referido ambiente em relação ao citado planejamento, definindo o foco deste último (competências $\mathrm{e}$ recursos internos ou a concorrentes $\mathrm{e}$ fornecedores, por exemplo);

c) síntese do posicionamento do ambiente em estudo em seu mercado de atuação;

d) diagnóstico de fatores internos $\mathrm{e}$ externos, mais especificamente as forças competitivas de concorrentes, fornecedores, substitutos e parceiros, os recursos e relações como pessoas, informações, finanças e estrutura física, forças e fraquezas, oportunidades e ameaças ambientais;

e) detalhamento da competência central do mesmo, que o diferencia de concorrentes e potencializa a procura do público-alvo por seus serviços;

f) definição de direcionamento estratégico, composto por visão, missão, valores e objetivos que pretende alcançar no futuro;

g) esboço propriamente dito da estratégia nos níveis de negócios, colaboração e crescimento, a ser seguida para o alcance do referido direcionamento, suportada pela competência central e demais recursos internos do ambiente estudado.

O artigo pretende apresentar componentes da prática do planejamento estratégico no ambiente acadêmico, bem como aspectos relevantes para sua efetiva inserção nesse mesmo contexto, viabilizando a replicação do processo aqui descrito por parte de qualquer entidade voltada à pesquisa.

\section{O grupo de pesquisa aplicada em ciência, informação e tecnologia}

Criado em 2007, o GP-CIT está instalado no Setor de Ciências Sociais Aplicadas da Universidade Federal do Paraná, no âmbito do Departamento de Ciência e Gestão da Informação. Sua coordenação caracteriza-o como jovial e interdisciplinar, cujas linhas de pesquisa extrapolam a dinamicidade natural do ambiente científico e são, a saber: educação continuada e corporativa com inserção ou não de tecnologia; engenharia ergonômica de software: teoria, modelos e metodologia; fundamentos e práticas do direito sobre o trabalho intelectual; gerência de projetos e informações; workflow aplicado a sistema de gestão para projetos digitais. (BRASIL, 2009).

São subordinados ao GP-CIT, o Laboratório de Mídias Digitais (Labmidi) e o Centro de Estudos 
em Realidade Virtual Aplicada (Cerva), que englobam, respectivamente, pesquisas em Educação e a relação dessa com Tecnologias da Informação, e; Arquitetura da Informação aplicada à Realidade Virtual.

A participação em editais de financiamento de projetos disponibilizados por entidades como o Conselho Nacional de Desenvolvimento Tecnológico (CNPq) e a Fundação Araucária permite ao GP-CIT obter recursos para aquisição de equipamentos, remuneração de colaboradores e desenvolvimento de produtos.

\section{Escopo do planejamento Estratégico}

\section{Demandas identificadas}

A recente formação do GP-CIT, paralela ao fato de que a cultura gerencial e de atividades desse encontra-se em construção, oportuniza a criação de medidas de planejamento estratégico ao grupo de pesquisa acadêmica. Tais medidas visam oferecer ao Grupo um posicionamento de destaque no ambiente em que atua, por meio de eficiência, eficácia e efetividade de ações e decisões.

Tais fatores vêm fundamentar as capacidades que o mercado competitivo (entendido como ambiente acadêmico) exige do GP-CIT. São eles: planejamento de objetivos, métodos, recursos financeiros, físicos, humanos e de conhecimento; agregação de inovação às atividades; encaminhamento adequado dos objetivos a serem atingidos.

Corresponder a tais capacidades demanda, essencialmente, que seja estabelecido um delineamento estratégico para estruturar e coordenar atividades em direção a um horizonte comum identificado como sendo a utilização de recursos e relacionamentos estratégicos para aquisição de vantagem competitiva, acrescida de decisões que agreguem o maior nível possível de certeza e de qualidade.
Considera-se que o delineamento supracitado é efetivado em quatro momentos:

a) à medida que fatores ambientais internos e externos ao Grupo são diagnosticados;

b) que a direção estratégica é estabelecida e difundida entre os integrantes;

c) que problemas estratégicos são identificados e solucionados mediante ações exequíveis no âmbito do Grupo;

d) que tais soluções são monitoradas por meio de controles específicos.

\section{Escopo: posicionamento no mercado}

Avalia-se que oferecer ao GP-CIT um posicionamento destacado no ambiente onde atua significa definir internamente e esclarecer externamente sua colocação atual no mesmo contexto, de modo que as atividades por ele desenvolvidas atendam uma parcela considerável das demandas de seu universo potencial de usuários, modificando constantemente o desempenho atual de atividades (PORTER, 1999).

Em entrevista junto à coordenação do Grupo, identificou-se o desconhecimento desse posicionamentoconsiderandooslimitesinternose externosà Universidade. Portanto, o planejamento estratégico teria como escopo fundamental posicionar o Grupo estrategicamente e fomentar sua visibilidade no âmbito da Universidade onde está localizado. Essa restrição de escopo não determina que o Grupo ignore ações em busca de parcerias, clientes e fornecedores externos, visto que o posicionamento é composto também da interação com esses atores. Enquanto espelho de uma estratégia caracterizada como ciclo analítico constituído de planos de ação, o plano estratégico advindo do escopo supracitado orienta o Grupo "ao cumprimento de seus objetivos fundamentais" (HARRISON, 2005, p. 36), identificado conforme as etapas de encaminhamento metodológico, apresentadas a seguir. 


\section{Diagnóstico}

\section{O ambiente de atuação do GP-CIT}

Para Harrison (2005, p. 35), o ambiente de atuação da uma organização consiste no contexto sobre o qual essa exerce influências e é, por este, influenciada.

O ambiente onde o GP-CIT atua constitui-se na comunidade científica local (UFPR) e global (fora dos limites da Universidade), que, por suas características peculiares - quando comparada a ambientes de negócio convencionais - apresenta influências e exigências específicas. Contém, inerentemente, o "diálogo e a competição sobre o conhecimento cientificamente válido" (BRASIL, 2009) que, de forma conjuntural, segundo Oliveira (2001, p. 10), apresenta constante movimento e formação contínua, o que impede que aqueles que nela atuem tomem posicionamento estático e inerte.

A análise desse ambiente constitui a primeira etapa metodológica da elaboração do plano estratégico do GP-CIT, que pode ser subdividida em enfoque externo e enfoque interno.

\section{Enfoque externo: ambiente geral e forças competitivas}

Segundo Chiavenato e Sapiro (2003), esse enfoque viabiliza a identificação de indicadores de tendências, a avaliação do ambiente de negócios, a análise concorrencial e a compreensão dos grupos estratégicos. Transparece, ainda, ameaças e oportunidades ambientais e os meios para contornar ou usufruir desses aspectos.

As forças competitivas (PORTER, 1999) do ambiente externo ao GP-CIT, ditam a rivalidade existente entre o núcleo de concorrentes diretos desse e viabilizam, segundo Harrison (2005, p. 61), a compreensão do posicionamento ideal desse frente a concorrentes atuais e potenciais, aos fornecedores, aos clientes e aos produtos substitutos. Oportunidades e fontes de vantagem competitiva surgem quando tais agentes são considerados, visto que seu poder de barganha influencia sobremaneira as atividades do Grupo.

Nesses termos, o alto poder de barganha de fornecedores e clientes, enquanto qualificadores de atividades do Grupo, e a menor influência de concorrentes potenciais e produtos substitutos devido à sua presença reduzida no ambiente supracitado, encaminharam à constatação de que:

a) a rivalidade entre concorrentes diretos no meio acadêmico-científico divide espaço com a colaboração, fator inerente ao próprio meio;

b) a participação de mercado é tida como aspecto intrínseco às atividades, sem contudo ser estabelecida como conceito estritamente necessário à atuação na academia;

c) a concorrência direta no meio acadêmico fundamenta-se em:

- presença em veículos de comunicação científica;

- recursos físicos e financeiros suficientes e abrangentes;

- qualificação de integrantes;

- contato consolidado com fornecedores.

Movimentações inerentes aos aspectos listados acima traduzem, segundo Harrison (2005), a aplicação da criatividade quando da busca em diminuir vantagens competitivas de concorrentes por parte das organizações. No contexto acadêmico, tal dinâmica competitiva refletese em fatores como as barreiras inerentes à cientificidade quanto à imitação e a flexibilidade em termos de desenvolvimento de pesquisas inovadoras.

Em resposta à vantagem competitiva almejada pelo GP-CIT, fundamentada nos fatores acima, seus concorrentes e demais atuantes no ambiente acadêmico podem agregar forças às suas próprias vantagens (BARNEY e HESTERLY, 2007, p. 82), sustentadas por projetos, pesquisas e formação acadêmica de integrantes diversificados, tanto pela diferenciação do público-alvo, como pela 
localização geográfica distinta. Contrariamente, esses atores podem reagir apoiando-se em elementos estratégicos variados em relação a recursos, comunicação, atendimento do público, entre outros fatores, visto que em ambiente de pesquisa científica, a competitividade é alcançada principalmente através de decisões e ações táticas (BARNEY e HESTERLY, 2007, p. 84).

\section{Enfoque interno: recursos e relações}

Esse enfoque, por sua vez, permite a avaliação competitiva de potencialidades e fragilidades da organização em questão, bem como da localização dos recursos que fundamentam suas capacidades e suas competências originárias de valor (CHIAVENATO e SAPIRO, 2003).

Como passos iniciais da análise do enfoque interno à estratégia do Grupo identificaram-se e caracterizaram-se os recursos, as relações e a visão voltada a aspectos endógenos relativos ao seu potencial estratégico. A categorização do valor identificado junto aos recursos originou a definição da competência central do Grupo, insumo para o direcionamento estratégico apresentado ao final do estudo.

Influenciam diretamente as atividades do Grupo os relacionamentos com os seguintes públicos: recursos humanos internos; grupos e pesquisadores parceiros; instituições financiadoras e comunidade científica, cujo foco é um conjunto de atividades pertinentes às suas áreas de atuação.

Considerando que relacionamentos internos e externos giram em torno da troca de benefícios entre as partes, no contexto do GP-CIT, tais fatores consistem em pesquisas e produtos desenvolvidos em parceria e pertinentes tanto às linhas de pesquisa integradas pelo Grupo quanto a outras que possam, porventura, criar aplicações multidisciplinares.

Quanto aos recursos mantidos pelo Grupo, aqueles de caráter intangível, humano, físico e financeiro agregam valor à atuação desse no ambiente acadêmico, consistindo em fontes de competitividade devido à sua peculiaridade e dificuldade de identificação em outros ambientes. $\mathrm{Na}$ academia, recursos de quaisquer naturezas especializam-se conforme a atuação dos agentes e, logo, correspondem a certa exclusividade. Percebeu-se que a utilização desses na exploração de oportunidades e na mitigação de ameaças de mercado relaciona-se com a capacidade do Grupo em direcionar competências mantidas por seus integrantes ao desenvolvimento de novas pesquisas e ao gerenciamento do processo criativo e de planejamento. Ainda que tais capacidades possibilitem ao Grupo "aproveitar [...] outros recursos que controla” (BARNEY e HESTERLY, 2007, p. 64), estas carecem de otimização e organização para aproveitamento pleno destes (HARRISON, 2005, p. 79) em direção a um efetivo horizonte estratégico de atuação.

\section{Análise Swot}

A partir dos conteúdos dispostos acima, realizouse a análise SWOT do GP-CIT, onde aspectos endógenos e exógenos são categorizados quanto às forças, fraquezas, oportunidades e ameaças relacionadas ao Grupo e sua atuação no ambiente acadêmico, e apresentados em ordem de importância no Quadro 1.

Fraquezas eameaças impedem o encaminhamento pleno do Grupo à vantagem competitiva. Parte da estratégia por ele empreendida deve, então, ser formulada de modo a minimizar ou, preferencialmente, eliminar tais fatores negativos e fomentar forças internas e oportunidades de mercado. Desta forma, estabelecer uma direção estratégica e definir objetivos de longo prazo é condição essencial à efetivação das oportunidades e necessidades acima apontadas, agregando qualidade às decisões tomadas e consolidando a vantagem competitiva do Grupo frente a seus competidores e às ameaças do ambiente.

\section{Competência central}

A competência central do GP-CIT consiste no "conjunto de habilidades e tecnologias [que 
Quadro 1 - Forças, fraquezas, oportunidades e ameças ambientais do GP-CIT

\begin{tabular}{|c|c|}
\hline $\begin{array}{l}\text { Forças } \\
\text { Ressaltam capacidades do Grupo e aspectos que viabilizam o } \\
\text { planejamento estratégico }\end{array}$ & $\begin{array}{l}\text { Oportunidades } \\
\text { Determinam possibilidades de atuação e posicionamento do } \\
\text { Grupo }\end{array}$ \\
\hline $\begin{array}{l}\text { a) posicionamento relativamente destacado no } \\
\text { Departamento de Ciência e Gestão da Informação e } \\
\text { no Setor de Ciências Sociais Aplicadas, consequente } \\
\text { horizonte para maior posicionamento na UFPR e fora } \\
\text { dela; } \\
\text { b) disposição à realização de planejamento estratégico; } \\
\text { c) pertinência dos projetos e capacidade de diversificação } \\
\text { do portfólio desses; } \\
\text { d) formação acadêmica da coordenação do Grupo nas } \\
\text { linhas de pesquisa integradas por esse; } \\
\text { e) manutenção de contatos e pesquisas conjuntas com } \\
\text { grupos parceiros. }\end{array}$ & $\begin{array}{l}\text { a) atualidade e abrangência das linhas de pesquisa } \\
\text { integradas pelo Grupo; } \\
\text { b) pouca difusão de pesquisas similares na Universidade, } \\
\text { proporcionando conjuntura para maior destaque do } \\
\text { Grupo em termos de posicionamento; } \\
\text { c) concorrência insignificante no âmbito da Universidade } \\
\text { e de pouca influência direta no âmbito além dessa } \\
\text { Instituição; } \\
\text { d) constante disponibilização de editais de financiamento, } \\
\text { para obtenção de recursos financeiros e certificação dos } \\
\text { projetos. }\end{array}$ \\
\hline $\begin{array}{l}\text { Fraquezas } \\
\text { Dificultam a atuação plena conforme objetivos } \\
\text { preestabelecidos } \\
\text { a) ausência de objetivos de longo prazo, para } \\
\text { posicionamento do Grupo; } \\
\text { b) dificuldade de planejamento estratégico para } \\
\text { alinhamento de atividades a objetivos, e de controle de } \\
\text { fatores ambientais e previsão de tendências relativas às } \\
\text { linhas de pesquisa; } \\
\text { c) ausência de controle das informações sobre o Grupo, } \\
\text { seus recursos e relações, e de disponibilização dessas em } \\
\text { local especifico e acessivel a todos os membros; } \\
\text { d) posicionamento de menor nível de destaque frente } \\
\text { àquele possivel, no ambiente de atuação; } \\
\text { e) necessidade de tomada de decisões imediatas, sem a } \\
\text { devida fundamentação informacional e com alto grau de } \\
\text { incerteza. }\end{array}$ & $\begin{array}{l}\text { Ameaças } \\
\text { Apresentam obstáculos ao alcance dos objetivos } \\
\text { estratégicos, táticos e operacionais } \\
\text { a) planos políticos, legislações e restrições em nível Federal; } \\
\text { b) consolidação de outros grupos de pesquisa com } \\
\text { foco semelhante ao do GP-CIT, e recursos e relações } \\
\text { diferenciados(as); } \\
\text { c) mudanças tecnológicas e descontinuação dos tópicos } \\
\text { desse gênero, estudados em projetos do Grupo. }\end{array}$ \\
\hline
\end{tabular}

Fonte: os autores.

possibilitam ao Grupo oferecer benefícios a seus públicos interessados, com os quais o Grupo assume compromisso de criação e aperfeiçoamento]" (PRAHALAD; HAMEL, 2005). Conforme os autores, tais habilidades e o uso da tecnologia permitem que essa competência sustente o Grupo em sua estratégia competitiva.

Advinda dos principais recursos mantidos pelo Grupo, a competência central surge do valor global a eles agregado em relação a cinco dimensões:
a) valor em si;
b) raridade;

c) diferenciação frente a outros grupos de pesquisa;

d) capacidade de organização interna;

e) exploração pela organização.

O Quadro 2 sistematiza tais dimensões em relação aos recursos do GP-CIT, apontando aqueles de maior relevância para a competitividade e que dão origem a principal competência de suas atividades.

Considerando-se as pesquisas desenvolvidas no âmbito do Grupo e os conhecimentos adquiridos e mantidos por integrantes em relação a essas (tais como foram assinaladas nas colunas do Quadro 2), verifica-se que tais recursos 
Quadro 2 - valor global de recursos do GP-CIT

\begin{tabular}{|l|l|l|l|l|l|}
\hline Recurso & Valioso & Raro & Diferenciado & $\begin{array}{c}\text { Organizado } \\
\text { internamente }\end{array}$ & $\begin{array}{c}\text { Explorado pelo } \\
\text { Grupo }\end{array}$ \\
\hline Pesquisas desenvolvidas & & & & \\
\hline Conhecimentos adquiridos & & & & \\
\hline Integrantes do Grupo & & & & \\
\hline $\begin{array}{l}\text { Certificação por órgãos de } \\
\text { fomento }\end{array}$ & & & & \\
\hline Montantes financeiros obtidos & & & & \\
\hline Instalações físicas & & & & \\
\hline
\end{tabular}

Fonte: adaptado de Barney e Hesterly (2007, p. 80).

agregam valor à atuação do GP-CIT no ambiente acadêmico. Portanto, podem ser definidos como estratégicos, ao mesmo tempo em que revelam a competência central a ser ressaltada pelo Grupo em suas atividades, potencializando a obtenção de vantagem competitiva sustentada.

\section{Direcionamento estratégico}

Segundo Harrison (2005, p. 110), a direção estratégica determina a identidade da organização, comunicando-a a públicos internos e externos e orientando processos decisórios em relação à estratégia da mesma organização.

A partir do escopo identificado para o planejamento estratégico do GP-CIT e do diagnóstico supracitado, estabeleceu-se a direção a ser seguida visando atingir o posicionamento almejado. Esse direcionamento reflete-se nos fatores indicados a seguir, cujo nível de abrangência decresce a cada tópico:

\section{Visão}

Ser referência em pesquisas multidisciplinares nas áreas de formação dos integrantes, com a capacidade de gerar e antecipar demandas e temáticas inovadoras relativas a tecnologias e aplicações nessas mesmas áreas de formação.

\section{Missão}

Atuar em pesquisas inovadoras e multidisciplinares, relacionadas à aplicação de conceitos e tecnologias nas áreas de formação dos integrantes, divulgando os resultados à comunidade científica e oferecendo benefícios também à comunidade em geral.

Valores

a) oferecer qualidade e compromisso no atendimento de demandas por pesquisas;

b) promover o apoio da Universidade e de outros apoiadores das atividades do Grupo, em todas as oportunidades pertinentes;

c) respeitar valores, idéias e críticas dos integrantes do Grupo, mantendo-o coeso;

d) manter idoneidade junto aos órgãos de fomento/financiadores, fortalecendo o relacionamento com tais instituições.

\section{Objetivos}

a) gerar pesquisas inovadoras, bem como novos paradigmas de atuação sobre tecnologias e aplicações relativas às linhas de pesquisa;

b) buscar e fortalecer contatos e parcerias pertinentes às linhas de pesquisa atendidas;

c) estimular a coesão e o comprometimento da equipe;

d) efetivar processos organizadamente e com boa estrutura informacional.

Estabelecer conteúdos para visão, missão, valores e objetivos do GP-CIT, contribui para que seu público-alvo compreenda sua atuação 
no ambiente acadêmico, incentivando a criação de relações entre o Grupo e potenciais parceiros, uma vez que os objetivos comuns são claramente identificados (HARRISON, 2005). Estratégias podem ser formuladas a partir do direcionamento aqui estabelecido, de modo a manter uma linearidade entre o posicionamento pretendido pelo GP-CIT e os desdobramentos desse em longo, médio e curto prazos, partindose do posicionamento atual.

Pode-se dizer que a configuração do ambiente acadêmico apresenta uma estrutura bem definida e não tão flexível em termos estratégicos e, nesse sentido, a identidade do GP-CIT pode ser coordenada e também representada por recursos e relações apontados anteriormente, reforçando o conceito da competência central mantida pelo Grupo.

\section{Formulação da estratégia}

A natureza do ambiente acadêmico tende aignorar, como já comentado acima, a competitividade nos moldes de empresas e organizações. Modelos de dinâmica competitiva adotados por concorrentes diretos tendem a ser similares, mas ainda assim permitem a formulação de estratégias de atuação para, como aponta Harrison (2005), competir no mercado e adotar posturas condizentes com competências centrais.

Tal pressuposto determina a formulação de estratégias competitivas para o GP-CIT, as quais suportam a atuação desse no ambiente acadêmico considerando horizontes de longo prazo.

Visto que a atuação do GP-CIT não prevê a aquisição simultânea de vantagens competitivas em diversos setores - entendida como estratégia de nível corporativo (BARNEY e HESTERLY, 2007) - as decisões estratégicas relacionadas ao Grupo comportarão os níveis de negócios em um âmbito reduzido de "mercado" e de colaboração.

\section{a) Estratégia no nível de negócio: diferenciação}

A abordagem estratégica selecionada para o nível de negócios no GP-CIT é de diferenciação, ressaltando a busca por vantagem competitiva através de aumento ou destaque do valor oferecido por produtos e serviços desenvolvidos em seu âmbito. Enquanto "expressão da criatividade" (BARNEY e HESTERLY, 2007, p. 131-137), essa abordagem busca vantagem competitiva principalmente por meio da ressalva de recursos (HARRISON, 2005).

Constatou-se que a diferenciação almejada pelo Grupo poderia apresentar-se por meio das seguintes dimensões:

a) características e complexidade dos projetos e pesquisas desenvolvidos, ou seja, o "foco direto nos atributos", refletidas no conjunto de processos e atividades do Grupo, cuja organização e desenvolvimento únicos e variam em complexidade conforme fontes de pesquisa, métodos utilizados e resultados obtidos. Tais características e processos são difíceis de serem reproduzidos por concorrentes ou substitutos;

b) localização geográfica do Grupo, considerando o índice mínimo de concorrência direta na Universidade onde esse está inserido e no âmbito de todo o estado;

c) customização, uma vez que projetos e produtos desenvolvidos no âmbito do GP-CIT têm caráter inédito em relação a escopo, características e complexidade, ou método de desenvolvimento;

d) reputação, determinante da "relação mais importante entre uma empresa e seus consumidores", que diferencia o Grupo à medida que sua imagem no mercado é construída única $\mathrm{e}$ exclusivamente por suas próprias ações e produtos;

e) atendimento e suporte, onde a associação entre ação e acompanhamento agrega valor a determinadas pesquisas conduzidas pelo Grupo e oferece, consequentemente, visibilidade junto ao 
mercado (BARNEY e HESTERLY, 2007, p. 133-137).

\section{b) Estratégia colaborativa}

Espaços onde atores "combinam recursos em um esforço para conseguir uma posição mais forte" (HARRISON, 2005, p. 145) e "cooperam no desenvolvimento, na produção ou na venda de produtos ou serviços" (BARNEY e HESTERLY, 2007), constituem as estratégias colaborativas. Nesses termos, o ambiente acadêmico, oferece possibilidades inúmeras em termos de colaboração enquanto meio dinâmico de desenvolvimento de inovações.

Percebeu-se que o GP-CIT tem, como contexto colaborativo, parcerias com outros grupos ou pesquisadores quando da construção conjunta de conhecimentos sobre determinado tema de competência dos parceiros, do compartilhamento desses conhecimentos para desenvolvimento de resultados específicos, do acesso, disponibilidade e uso de meios de comunicação pela comunidade científica e pelos parceiros.

Segundo Barney e Hesterly (2007), o valor dessa estrutura colaborativa se dá pela melhoria de desempenho agregada aos processos do Grupo, considerando não o retorno econômico, mas o prestígio e a visibilidade adquiridos quando da entrega de produtos, serviços, ou da apresentação de resultados a toda a comunidade científica. Tal premissa determina que benefícios advindos de produções colaborativas onde o GP-CIT está inserido são obtidos à medida que os parceiros operam com "compromisso, coordenação e confiança”" (BARNEY e HESTERLY, 2007, p. 268).

Conforme o contexto acima explorado, estabeleceu-se que a estratégia colaborativa a ser empreendida pelo GP-CIT deve ressaltar parcerias atuais e buscar novas relações visando um nível ideal de confiança, onde é refletida a capacidade do Grupo em comunicar-se com semelhantes e produzir resultados adequados às demandas. Resultados como produção bibliográfica, técnica, científica, entre outros, devem também ser almejados ininterruptamente.

Tais objetivos foram formulados de modo a contribuir para o encaminhamento do Grupo ao posicionamento como referência na atuação relativa às suas linhas de pesquisa, considerando a Universidade Federal do Paraná e instituições parceiras como principais mercados alvo.

\section{c) Estratégia de crescimento}

O crescimento do GP-CIT no mercado em que atua deve ser mantido como foco estratégico, traduzido pelo desenvolvimento de pesquisas e produtos em consonância com a direção estabelecida, no longo prazo. No entanto, o período de implementação deve abordar a chamada "estratégia temporária de nãocrescimento" (HARRISON, 2005, p. 173), cujo intuito, segundo o autor, é de reforçar as bases estratégicas da organização visando obter maior crescimento futuramente.

\section{Considerações finais}

Ao longo do estudo de cada uma das etapas acima detalhadas, identificou-se que o Grupo de Pesquisa Aplicada em Ciência, Informação e Tecnologia pode melhorar seu desempenho pela implementação das estratégias de negócio e colaborativa.

Tal processo de implementação é subsidiado pelo diagnóstico realizado e no fato de que a cultura do Grupo encontra-se em formação e pode alinhar-se à direção estratégica aqui estabelecida, de modo que a visibilidade e posicionamento de mercado possam ser estimulados principalmente pelo uso de recursos e competências estratégicos. Considera-se ainda que o diagnóstico empreendido é imprescindível ao desenvolvimento de um plano estratégico com foco no ambiente acadêmico, visto que as peculiaridades a pesquisa acadêmica exigem a identificação clara da realidade para que a estratégia torne-se viável e compatível com esse contexto. 
Retomando questões culturais do GP-CIT, nota-se que as definições estratégicas estabelecidas a partir do estudo de caso integram empreendedorismo e inovação a uma organização que, cotidianamente, pouco volta esforços à atuação sustentada pela visão além do tático e operacional. Entendese que, ao se buscar extrapolar esses limites se deve igualmente reconhecer um processo que se agregará paulatinamente às decisões tomadas no ambiente acadêmico, oferecendo-lhe perspectivas sólidas de atividade à medida que competidores $\mathrm{e}$ colaboradores têm noção do papel de sua atuação no mercado e do rumo que esse segue conforme pesquisas são desenvolvidas.

Especificamente em relação ao alcance dos objetivos embutidos nas estratégias formuladas, vale ressaltar que, apesar das características diferenciadas do ambiente acadêmico, riscos mostram-se presentes. No que diz respeito ao GP-CIT, há o risco de falha associada à estratégia de diferenciação, cuja concepção pode considerar demasiadamente características e benefícios implícitos de pesquisas desenvolvidas sem que esses sejam efetivamente percebidos pelos públicos-alvo. A atualidade dessas pesquisas também consiste em risco de alto potencial de interferência no posicionamento de mercado por parte do Grupo, visto que oferece espaços de atuação e novos mercados a concorrentes. Esses e outros aspectos interferem, ainda, na estratégia colaborativa estabelecida, uma vez que a confiança entre os parceiros pode ser abalada pela dinâmica competitiva do ambiente.

Ainda que se considerem os riscos supracitados, o plano estratégico formulado para o GP-CIT abarca uma perspectiva holística e integrada, tendo como pressuposto que não apenas ações de implementação da estratégia devem ser empreendidas, mas também a sensibilização para o chamado pensamento estratégico enquanto caráter inovador do Grupo frente à atual cultura da organização.

Entende-se que a inserção de tal pensamento nessa cultura poderá originar a formulação de novos objetivos estratégicos conforme o Grupo avança rumo à direção estabelecida orientando-se a um posicionamento macro de mercado, à eficácia e efetividade relativas às dimensões informativas, de processos internos, de tecnologias, de aprendizado e crescimento, de clientes e agentes externos e de finanças.

Táticas e operações para implementação das estratégias e contínuo monitoramento de objetivos desse gênero são de responsabilidade do GP-CIT enquanto organização, uma vez que a internalização desses aspectos é fator sumariamente importante para o alcance de visão e missão de negócios a partir do mercado identificado.

\section{Referências}

BARNEY, J. R.; HESTERLY, W. S. Administração estratégica e vantagem competitiva. São Paulo: Pearson Prentice Hall, 2007.

BRASIL. Ministério da Ciência e Tecnologia. Conselho Nacional de Desenvolvimento Científico e Tecnológico. Diretório dos grupos de pesquisa no Brasil. Disponível em: <http://dgp.cnpq.br/ buscaoperacional/detalhegrupo.jsp?grupo $=01036072 \mathrm{~A}$ JV4CL\#identificacao>. Acesso em: 6 abr. 2009.

CHIAVENATO, I.; SAPIRO, A. Planejamento estratégico. Rio de Janeiro: Elsevier, 2003.

HARRISON, J. S. Administração estratégica de recursos e relacionamentos. Porto Alegre: Bookman, 2005.

OLIVEIRA, M. de. A pesquisa científica na ciência da informação: análise da pesquisa financiada pelo CNPq. Perspectivas em Ciência da Informação, Belo Horizonte, v. 6, n. 2, p. 143-156, jul./dez. 2001.

PORTER, M. E. Competição - on competition: estratégias competitivas essenciais. 14. Reimp. Rio de Janeiro: Elsevier, 1999.

PRAHALAD, C. K.; HAMEL, G. Competindo pelo futuro: estratégias inovadoras para obter o controle do seu setor e criar os mercados de amanhã. Rio de Janeiro: Elsevier, 2005. 
Strategic planning for the academic environment: a case study of a research group from the Federal University of Paraná

\begin{abstract}
Introduction: Competition on academic research environments differs from that in the competitive enterprise markets. Strategic objectives in the first case deal with visibility and positioning between researchers and in the research groups market. The Applied Research Group for Science, Information and Technology (GP-CIT) felt the urge for engaging into a strategic planning process, looking for aggregate value to its decision processes, establishing directions and strategies. Internal and external assessments to GP-CIT revealed favorable characteristics towards strategic planning, aiming at reinforcing the potential for its resources, competences and opportunities. Method: Applied research involving the following steps: characterization of the environment, identifying the main type of demand in relation to planning as well as directed the Group focus setting; synthesis of the positioning of the environment outside its market area; diagnosis of internal and external factors; detailment of central expertise; definition of the strategic direction; outlining the strategy in the levels of business collaboration and growth. Results: The characteristics of the internal culture and external GP-CIT are favorable to the realization of strategic planning focused to enhance its resources, skills and opportunities. These fundamental aspects of the design of the strategic direction can be pursued by the Group in the academic environment on long-term vision supporting its mission, goals and business values. Differentiation strategies, collaboration and growth objectives were formulated in order to foster the activity of the GP-CIT in the academic environment, considering its competitive dynamics. Conclusions: Implementation of strategies should follow careful steps and decisions, to achieve competitive prospect based on solid performance. Strategic thinking, while a holistic view, is to be inserted into the Group's culture in order to change not only processes related to it, but the whole paradigm of activities and its competitiveness in the academic environment.
\end{abstract}

\section{Keywords}

Strategic planning; Universidade Federal do Paraná; Research group; Competitiveness; Information Management.
Recebido em 21 de abril de 2011

Aceito em 23 de abril de 2011

${ }^{1}$ Graduada em Gestão da Informação, Mestranda em Ciência, Gestão e Tecnologia da Informação - UFPR. Estudante de pós-graduação (Mestrado) - UFPR.

ac.greef@gmail.com

${ }^{2}$ Graduado em Gestão da Informação, Mestrando em Ciência, Gestão e Tecnologia da Informação - UFPR. Estudante de pós-graduação (Mestrado) - UFPR.

franciscodaniel@gmail.com

${ }^{3}$ Graduado em Ciências Econômicas, Especialista em Gestão Empresarial, Mestre e Doutor em Administração de Sistemas de Informação - FGV-SP. Professor adjunto - UFPR/DeCiGI. ncastilho@ufpr.br

\section{Como citar este artigo}

GREEF, A. C.; COSTA, F. D. de 0.; CASTILHO JR, N. C. de C. Plano estratégico para o ambiente acadêmico: estudo de caso em grupo de pesquisa da Universidade Federal do Paraná. AtoZ, Curitiba, v. 1, n. 1, p. 50-60, jan./jun. 2011. Disponivel em: <www.atoz.ufpr.br>. Acesso em: 